Supplement of Earth Syst. Dynam., 7, 371-384, 2016

http://www.earth-syst-dynam.net/7/371/2016/

doi:10.5194/esd-7-371-2016-supplement

(c) Author(s) 2016. CC Attribution 3.0 License.

(c) (i)

Earth System
Dynamics

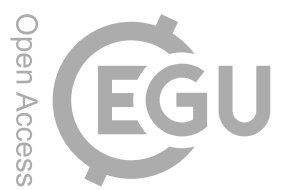

Supplement of

\title{
Atmospheric rivers moisture sources from a Lagrangian perspective
}

A. M. Ramos et al.

Correspondence to: Alexandre M. Ramos (amramos@fc.ul.pt)

The copyright of individual parts of the supplement might differ from the CC-BY 3.0 licence. 


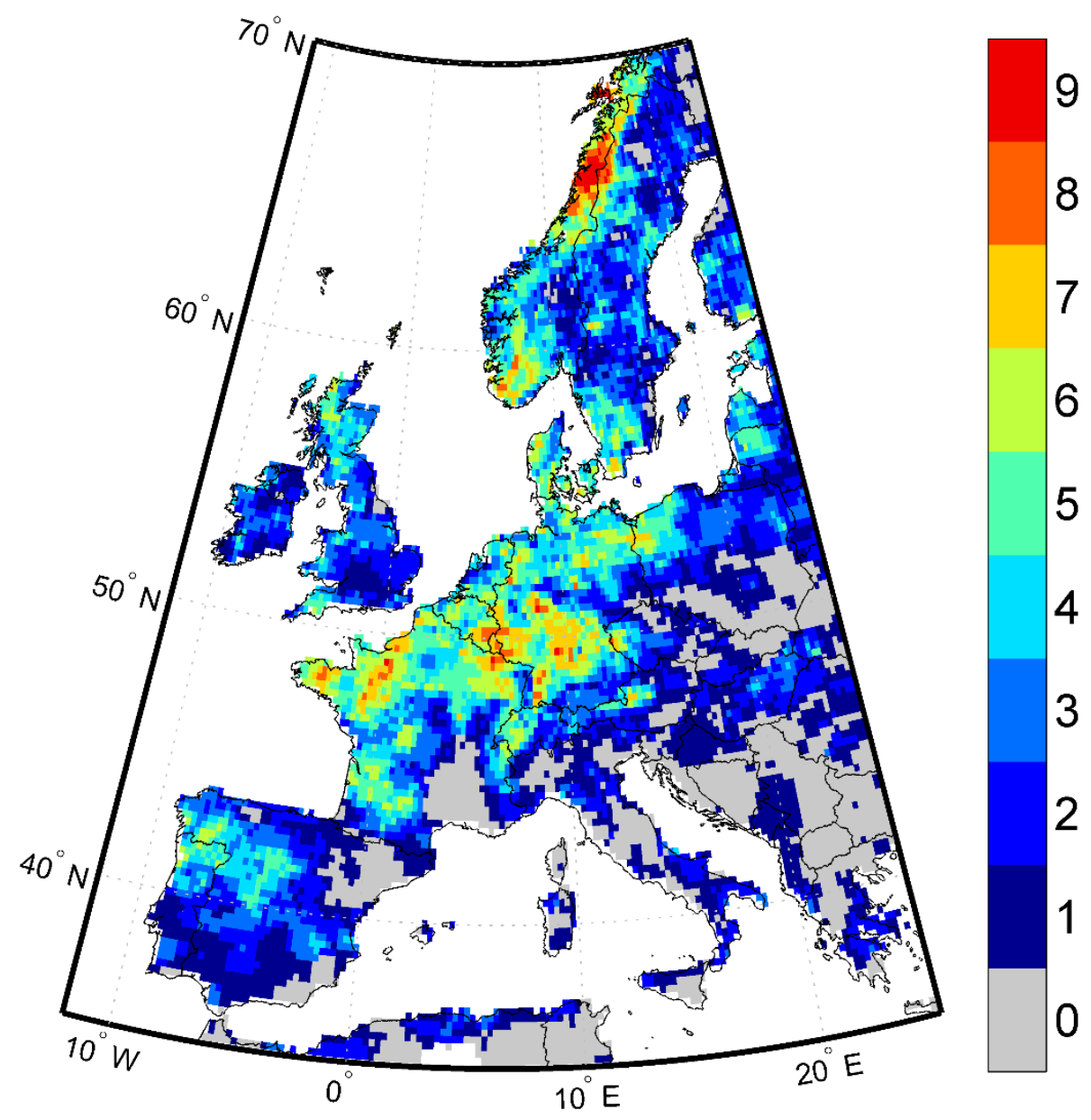

Figure S1. The number of Top 10 annual maxima precipitation events (for the extended winter months) related to Atmospheric Rivers. 

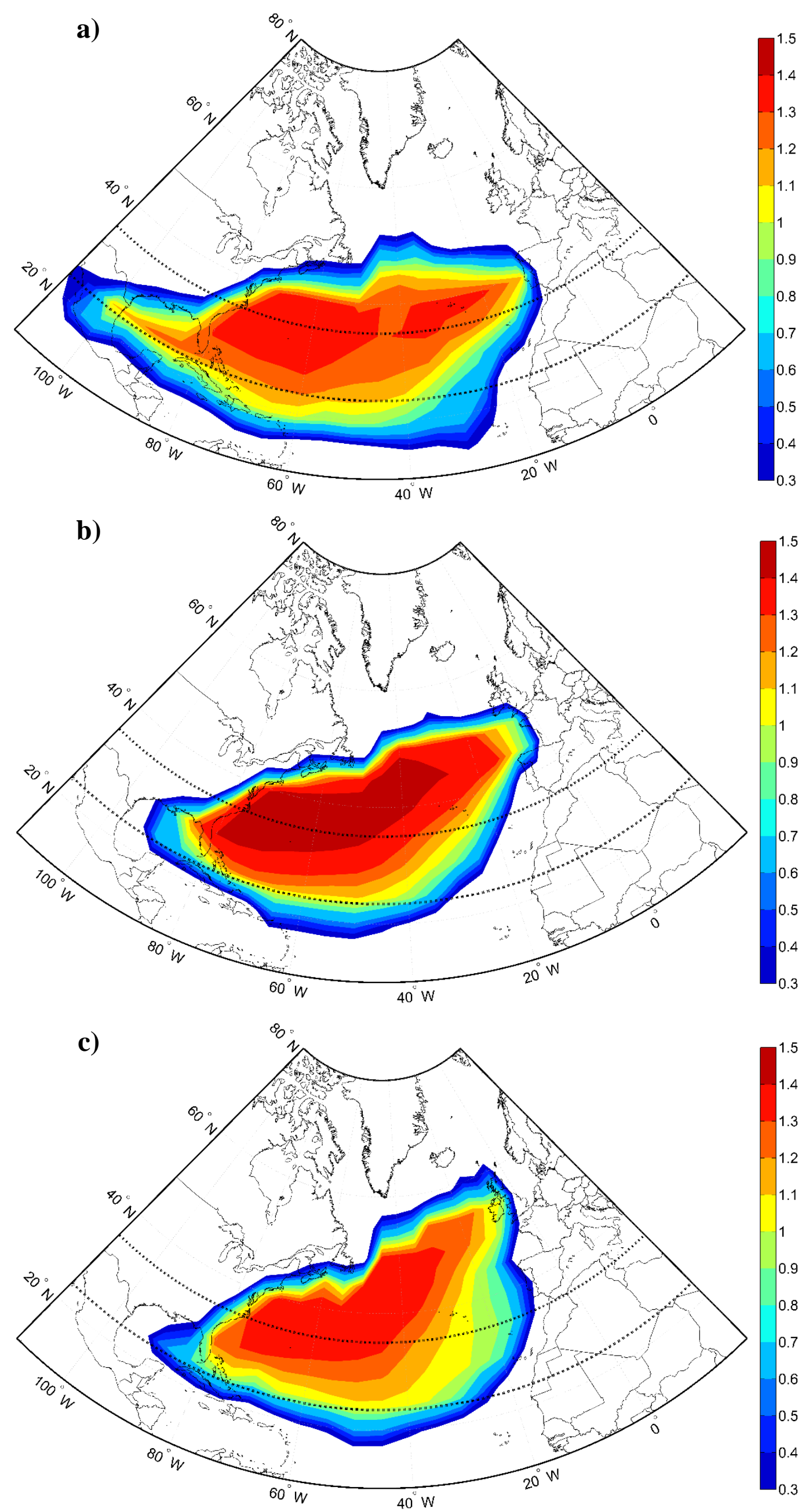

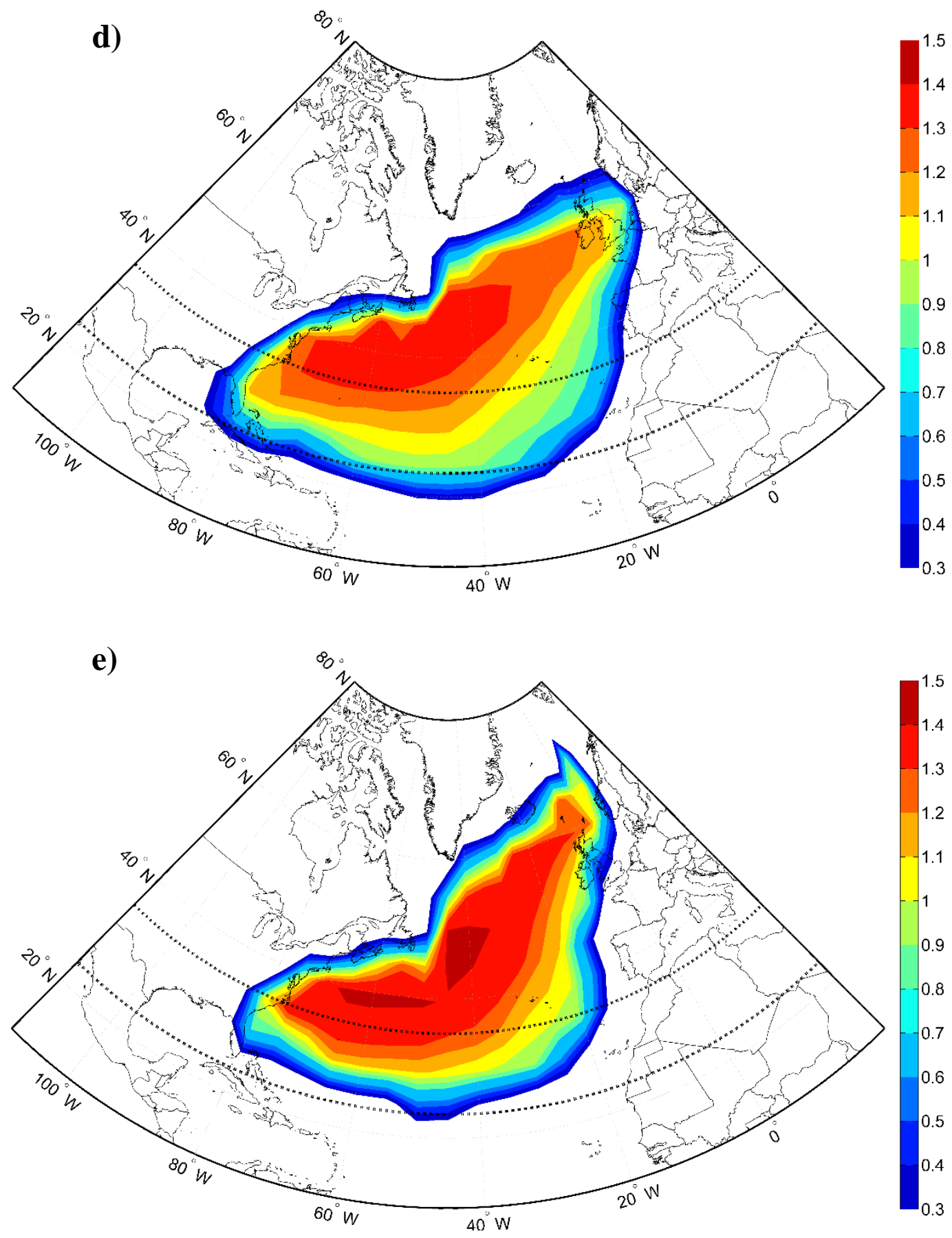

Figure S2. Track density (\%) of the air parcels used to compute the anomalous moisture uptake (at a $5^{\circ}$ by $5^{\circ}$ grid cell) for a) Iberian Peninsula, b) France, c) UK, d) South Scandinavia and the Netherlands, and e) North Scandinavia. 
Values of $(E-P)>0$ Anomaly by Longitude
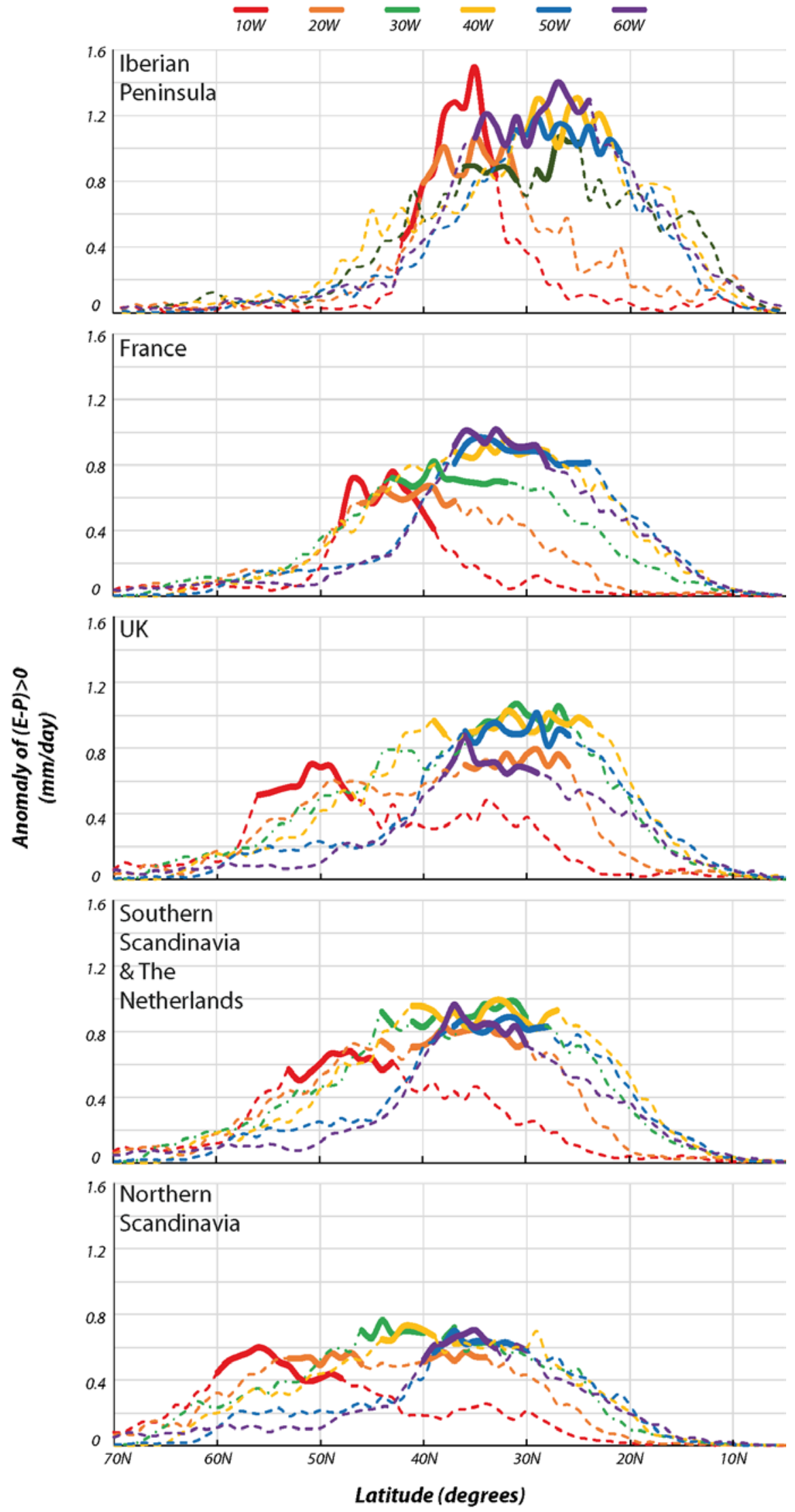

Figure S3. Longitudinal cross section of the anomaly values of (E-P) $>0$ field [(E-P)An] for each studied domain every 10 degrees: $10^{\circ} \mathrm{W}$ (red line), $20^{\circ} \mathrm{W}$ (orange), $30^{\circ} \mathrm{W}$ (green), $40^{\circ} \mathrm{W}$ (yellow), $50^{\circ} \mathrm{W}$ (blue), and $60^{\circ} \mathrm{W}$ (purple). The bold line shows those values over the 90th percentile of each series (values shown in Table 4). Units in $\mathrm{mm} /$ day. 